\title{
Circulatory and Respiratory Complications of Carbon Dioxide Insufflation
}

\author{
C.N. Gutt ${ }^{a}$ T. Oniu ${ }^{b}$ A. Mehrabi ${ }^{a}$ P. Schemmer ${ }^{a}$ A. Kashfib T. Kraus ${ }^{a}$ \\ M.W. Büchler ${ }^{\mathrm{a}}$
}

Departments of a General, Visceral and Transplant Surgery and bexperimental Surgery, University of Heidelberg, Heidelberg, Germany

\section{Key Words}

Carbon dioxide insufflation · Pneumoperitoneum •

Laparoscopic pathophysiological changes

\begin{abstract}
Background: Although providing excellent outcome results, laparoscopy also induces particular pathophysiological changes in response to pneumoperitoneum. Knowledge of the pathophysiology of a $\mathrm{CO}_{2}$ pneumoperitoneum can help minimize complications while profiting from the benefits of laparoscopic surgery without concerns about its safety. Methods: A review of articles on the pathophysiological changes and complications of carbon dioxide pneumoperitoneum as well as prevention and treatment of these complications was performed using the Medline database. Results: The main pathophysiological changes during $\mathrm{CO}_{2}$ pneumoperitoneum refer to the cardiovascular system and are mainly correlated with the amount of intra-abdominal pressure in combination with the patient's position on the operating table. These changes are well tolerated even in older and more debilitated patients, and except for a slight increase in the incidence of cardiac arrhythmias, no other significant cardiovascular complications occur. Al-
\end{abstract}

though there are important pulmonary pathophysiological changes, hypercarbia, hypoxemia and barotraumas, they would develop rarely since effective ventilation monitoring and techniques are applied. The alteration in splanchnic perfusion is proportional with the increase in intra-abdominal pressure and duration of pneumoperitoneum. Conclusion: A moderate-to-low intra-abdominal pressure $(<12 \mathrm{~mm} \mathrm{Hg}$ ) can help limit the extent of the pathophysiological changes since consecutive organ dysfunctions are minimal, transient and do not influence the outcome.

Copyright $@ 2004$ S. Karger AG, Basel

\section{Introduction}

The $\mathrm{CO}_{2}$ pneumoperitoneum induces hemodynamic, pulmonary, renal, splanchnic and endocrine pathophysiological changes. Most of them are not clinically significant if appropriate anesthetic care is provided. In some cases complications can develop depending on intra-abdominal pressure, the amount of $\mathrm{CO}_{2}$ absorbed, the circulatory volume of the patient, the ventilation technique used, the underlying pathologic conditions, and the type of anesthesia. Adequate monitoring and correct management is

\section{KARGER \\ Fax +41613061234 \\ E-Mail karger@karger.ch \\ www. karger.com \\ (C) 2004 S. Karger AG, Basel \\ 0253-4886/04/0212-0095\$21.00/0 \\ Accessible online at: \\ www. karger.com/dsu}

Carsten N. Gutt, MD

Department of General, Visceral and Transplant Surgery, University of Heidelberg Im Neuenheimer Feld 110, DE-69120 Heidelberg (Germany)

Tel. +4962215636334, Fax +496221565450

E-Mail Carsten_Gutt@med.uni-heidelberg.de 
important to prevent the development of complications. There are efficient prevention methods for each type of complication to profit from the benefits of laparoscopic surgery without concerns regarding its safety.

\section{Cardiovascular System}

The cardiovascular system is one of the most challenged systems of the human body during laparoscopy. Changes occurring during $\mathrm{CO}_{2}$ pneumoperitoneum result from two main factors: hypercarbia (and the subsequent acidosis) and increased intra-abdominal pressure.

\section{Hypercarbia and Acidosis}

$\mathrm{CO}_{2}$ is highly soluble and therefore is very rapidly absorbed from the peritoneal cavity into circulation. Because absorbed $\mathrm{CO}_{2}$ can only be excreted through the lungs, hypercarbia can only be avoided by a compensatory hyperventilation by increasing the tidal volume of ventilation in anesthetized patients. Hypercarbia can also develop as a result of a highly increased peritoneal absorption of $\mathrm{CO}_{2}$ and an insufficiently increased exhaustion of $\mathrm{CO}_{2}$. Absorption of $\mathrm{CO}_{2}$ is increased particularly during prolonged surgery using high intra-abdominal pressure. Exhaustion of $\mathrm{CO}_{2}$ is reduced in patients with compromised cardiopulmonary function and restricted $\mathrm{CO}_{2}$ clearance [1]. Also, the compensatory hyperventilation is impeded by the Trendelenburg position or a high intraabdominal pressure, which cause a cephalad displacement of the diaphragm (resulting in reduction of lung volumes) and a restriction in diaphragmatic mobility. In these conditions, severe hypercarbia can develop despite aggressive hyperventilation. It should be stressed that intra-abdominal pressure has a major role in the development of hypercarbia since it both increases the absorption and decreases the exhaustion of $\mathrm{CO}_{2}$.

Hypercarbia and acidosis can cause hemodynamic changes by direct action on the cardiovascular system and by an indirect action through sympathoadrenal stimulation $[1,2]$. The direct effect of carbon dioxide and acidosis can lead to decreased cardiac contractility, sensibilization of myocardium to the arrhythmogenic effects of catecholamines and systemic vasodilatation. The centrally mediated, autonomic effects of hypercarbia lead to a widespread sympathetic stimulation resulting in tachycardia and vasoconstriction counteracting the direct vasodilatatory effect.

\section{Increased Intra-Abdominal Pressure}

Increased intra-abdominal pressure during pneumoperitoneum triggers several pathophysiological mechanisms independently of the type of used gas. The most important mechanism of the neurohumoral response of the vasopressin and renin-angiotensin-aldosterone system is the sympathetic stress response [2] including vagal reflexes. The increased intra-abdominal pressure also leads to a mechanical impairment of the venous blood return leading to an increase in venous pressure of the lower extremity while decreasing the cardiac preload. Depending on the extent of above mentioned mechanisms there will be an increase in systemic vascular resistance and pulmonary vascular resistance resulting in an increased afterload. The development of hemodynamic changes depends on the functional reserve of the heart. There may be a decrease in cardiac output and hypotension without an increase in the heart rate.

\section{Clinical Studies of Hemodynamic Changes}

Cardiovascular changes have been characterized by many clinical studies [3-8, 27]. Most of these studies reported increased systemic and pulmonary vascular resistance and reduction of cardiac index when laparoscopy was performed at about $15 \mathrm{~mm} \mathrm{Hg}$ and head up tilt $10^{\circ}$. Joris et al. [3], using invasive monitoring, observed a significant increase in mean arterial pressure (35\%) after peritoneal insufflations, along with an increase of systemic vascular resistance (65\%) and pulmonary vascular resistance $(90 \%)$, and a decrease in cardiac index (20\%), while the pulmonary capillary wedge pressure and central venous pressure increased. They suggested that the decrease in cardiac index can be partly explained by an increase in systemic vascular resistance.

Using lower insufflation pressures, changes were milder and transient. Three minutes after the onset of pneumoperitoneum at the pressure of $8-12 \mathrm{~mm} \mathrm{Hg}$, Branche et al. [7] observed a $25.7 \%$ increase in mean arterial pressure, a $49 \%$ increase in left ventricular end-systolic wall stress (a measure of left ventricular afterload ) and a 17\% decrease in fractional area shortening (a measure of left ventricular function-contractility). All measured variables returned to preinsufflation values after $30 \mathrm{~min}$ of pneumoperitoneum and thereafter were no longer significantly affected by postural changes $\left(10^{\circ}\right.$ head-up position $)$ or pneumoperitoneum exsufflation.

A further reduction of the insufflation pressure was possible in children. During laparoscopic fundoplication for gastroesophageal reflux performed in the head-up position $\left(10^{\circ}\right)$ and at $5 \mathrm{~mm} \mathrm{Hg}$, an increase of $22 \%$ in CI

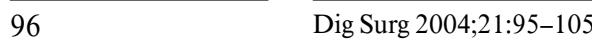


was recorded, along with a $21 \%$ increase in mean arterial pressure and a $17 \%$ increase in heart rate [9]. The results of all these above mentioned studies illustrate the hemodynamic changes depend directly on intra-abdominal pressure.

\section{Cardiovascular Complications}

The pathophysiological cardiovascular changes commonly occur but are well managed intraoperatively. The 'true' complications are represented by hypertension, hypotension, arrhythmias, and cardiac arrest.

Hypertensive episodes are dangerous because of their potential risk for hemorrhagic stroke, pulmonary edema and cardiac decompensation. The true incidence of hypertensive episodes is unknown, mainly because of the impact of pharmacological interventions that most of them are very efficient in controlling hypertention. But its incidence seems to be higher at the beginning of insufflations, when the increasing (but still below $10 \mathrm{~mm} \mathrm{Hg}$ ) intra-abdominal pressure increases the venous return by reducing the blood volume in the splanchnic vasculature. This increased preload augments cardiac output and arterial pressure $[10,11]$. This situation commonly occurs in patients having sufficient intravascular volume loading, i.e. $\sim 10 \mathrm{ml} / \mathrm{kg}$ prior to the induction of pneumoperitoneum, a loading which is nowadays standard for the prevention of hypotention.

Hypotension is a rare but serious complication occurring in up to $13 \%$ of laparoscopies [12]. It occurs mainly when intra-abdominal pressure exceeds $20 \mathrm{~mm} \mathrm{Hg}$ due to compression of the inferior vena cava. Venous return from the lower half of the body is impeded resulting in a reduction of cardiac output and hypotension. High intrathoracic pressure during intermittent positive pressure ventilation further impairs venous return and cardiac output, particularly if positive end-expiratory pressures are also applied. A vagal response can be involved in some cases. Since the central venous pressure rather reflects the intrathoracic pressure than the venous return, intraoperative invasive monitoring by a pulmonary artery catheter is required in patients with compromised cardiac function in order to ensure the required effective circulating blood volume to avoid hypotension.

The insufflation of gas into the peritoneal cavity can provoke arrhythmias. Their incidence is as high as 14$27 \%$ of laparoscopies [13] which is higher than in 'open' surgery. There should be a distinction between sinus tachycardia and ventricular extrasystoles which are due to the release of catecholamines and the more life-threatening bradyarrhythmias (sinus bradycardia, nodal rhythm, atrio-ventricular dissociation and asystole) which are due to a vagal-mediated cardiovascular reflex initiated by rapid stretching of the peritoneum at the beginning of peritoneal insufflation [12,14]. The incidence of arrhythmias is increased in the use of $\mathrm{CO}_{2}$ compared to other gases. It results from the myocardial irritability induced directly by $\mathrm{CO}_{2}$. Most arrhythmias are transient and respond to the reduction of intra-abdominal pressure and $100 \% \mathrm{O}_{2}$ hyperventilation $[12,14]$.

Cardiac arrest has been reported in 2-20 of 100,000 laparoscopies [13]. Although there are no studies directly comparing the incidence of cardiac arrest in laparoscopic and 'open' surgery, the above mentioned numbers are slightly increased compared to the anesthetic intraoperative cardiac arrest rate of 10/100,000 calculated for general surgeries between 1979-1988 [15, 16]. Among the causes of cardiac arrest there are two particularly associated to laparoscopy: the profound vasovagal response to rapid peritoneal distension and gas embolism.

\section{Prevention of Cardiovascular Complications}

Based on the knowledge of the pathophysiological mechanisms of possible complications, some prophylactic actions can be implemented:

Preoperative intravascular loading $(10 \mathrm{ml} / \mathrm{kg})$ ensures an adequate cardiac preload; otherwise the intra-abdominal pressure combined with the head-up tilt position may significantly decrease the cardiac index up to $50 \%[2,17-$ 20]. Case reports of cardiovascular collapse occurring in hypovolemic patients during laparoscopy justify the importance of this procedure.

Intermittent pneumatic compression effectively increases venous return and cardiac preload [21].

Invasive hemodynamic monitoring is required for ASA III and IV patients, including a pulmonary artery catheter for central venous pressure, pulmonary artery pressure [17, 22, 23].

Pharmacological therapy of hypertension, hypotension, and arrhythmia should be available.

Slow insufflation is essential to reduce the fatal consequences of gas embolism (in case of accidental intravascular insufflation) but mainly avoids vasovagal reflexes leading to collapse, arrhytmias and cardiac arrest.

Low intra-abdominal pressure is required, although the optimal pressure cannot be defined. Some procedures were feasible at 5-7 $\mathrm{mm} \mathrm{Hg}[25,26]$, but the required abdominal distension varies with surgical procedure, anatomical conditions and myorelaxation. The recommendation is to apply the lowest possible pressure level for each particular case. 
Extreme positioning is to be avoided, since it may have an influence both on cardiac preload and ventilation [27]. If certain extreme positions are required for a short time during some procedures, all other possible actions have to be taken in order to get over this critical period.

\section{Lungs and Gas Exchange}

\section{Pulmonary Changes}

During pneumoperitoneum the diaphragm is shifted upwards and the abdominal part of the chest wall is stiffened resulting a reduction of the total volume of the lungs, a significant decrease up to $35-40 \%$ in pulmonary compliance and a marked increase in the maximum resistance of the respiratory system [28-31]. Although the decrease in functional residual capacity promotes a ventilation-perfusion mismatch and an intrapulmonary shunting which may lead to hypoxemia [32], this occurs rarely in patients with normal preoperative pulmonary function. Without controlled hyperventilation an increase in the end-tidal carbon dioxide pressure by $10 \mathrm{~mm} \mathrm{Hg}$ develops. This is why the ventilatory pattern needs to be adjusted, and ventilation with large tidal volumes $(12-15 \mathrm{ml} / \mathrm{kg}$ ) to be performed in order to prevent progressive alveolar atelectasis and hypoxemia and to allow $\mathrm{CO}_{2}$ elimination. Although ventilation with positive end-expiratory pressure significantly improves pulmonary gas exchange [33, 34] and preserves arterial oxygenation during prolonged pneumoperitoneum [35] it should be noted that positive end-expiratory pressure in the presence of elevated intraabdominal pressure, increases the intrathoracic pressure and produces marked reduction in cardiac output. Therefore, it should be applied cautiously [36-39]. A modern ventilation technique is the 'alveolar recruitment strategy', consisting of manual ventilation to an airway pressure of $40 \mathrm{~cm} \mathrm{H}_{2} \mathrm{O}$ for 10 breaths over $1 \mathrm{~min}$, followed by usual mechanical ventilation with mild positive end-expiratory pressure $\left(5 \mathrm{~cm} \mathrm{H}_{2} \mathrm{O}\right)$. This improves arterial oxygenation intraoperatively during laparoscopy, without clinical cardiovascular compromise or respiratory complications [40]. Since up to 120 liters of $\mathrm{CO}_{2}$ can be stored in the human body during pneumoperitoneum, a prolonged mechanical ventilation is needed postoperatively in some cases until $\mathrm{CO}_{2}$ is eliminated completely [41].

\section{Pulmonary Complications}

Pulmonary complications are represented by hypoxemia, barotrauma, pulmonary edema, and atelectasis. Gas embolism, subcutaneous emphysema, pneumotho- rax, pneumomediastinum and pneumopericardum are considered distinct complications of laparoscopy and are discussed separately.

Only patients with compromised cardiopulmonary function such as emphysema and chronic obstructive pulmonary disease are at risk for the development of hypoxemia. If appropriate ventilation and oxygen administration are not able to reverse hypoxemia, conversion to open surgery may be required. Most of the patients with normal cardiopulmonary function will surpass these pathophysiological changes without developing hypoxemia or severe hypercapnia. Elevated airway pressures and decreased compliance could be associated with pulmonary barotrauma, which may occur as an immediate pneumothorax. This is more a theoretical assumption cited by some authors [19], but in the literature there are no such case reports of barotrauma due to inadvertent ventilation during laparoscopy. Although there is an important impairment of pulmonary function and gas exchange during laparoscopy, the recovery of pulmonary function is more rapid and the rate of pulmonary sequelae (atelectasis) or complications (pneumonia) is lower than after open surgical procedures, irrespective to the magnitude of the procedures or age of the patient [42-45].

\section{Gas Embolism}

Clinically apparent carbon dioxide embolism is a rare complication of laparoscopic surgery $(0.0014-0.6 \%$ of laparoscopies) [46-48] but it is associated with a high mortality rate of $28 \%$ [13].

The major cause leading to gas emboli is the misplacement of the Veress needle directly into a vein or parenchymal organ, but smaller amounts of gas may also enter circulation through an opening in any injured vessel, either in the abdominal wall or at the operative site. Therefore it is not surprising, that $60 \%$ of symptomatic cases occur during initial insufflation. There is level I evidence that the Hasson technique for establishing pneumoperitoneum is safer than the Veress needle technique; the incidence of gas embolism reported by a systematic review was $0.001 \%(7 / 489,000$ cases $)$ for the Veress needle while no such complication occurred in more than 12,000 cases using the Hasson technique [46]. Therefore the latter is recommended to be used instead of the Veress needle in all cases. The risk of symptomatic gas emboli primarily depends on the type of gas and its solubility. Because of their lower solubility compared to $\mathrm{CO}_{2}$, the other gases including helium and argon, as well as nitrogen, oxygen
98

Dig Surg 2004;21:95-105
Gutt/Oniu/Mehrabi/Schemmer/Kashfi/ Kraus/Büchler 
Table 1. Comparison of gases used for pneumoperitoneum

\begin{tabular}{lllll}
\hline Characteristic & $\begin{array}{l}\text { Carbon } \\
\text { dioxide }\end{array}$ & $\begin{array}{l}\text { Nitrous } \\
\text { oxide }\end{array}$ & Argon & Helium \\
\hline Solubility (ml per 100 ml of water) & 170 & 130 & 6 & 1 \\
\hline Supports combustion? & no & yes & no & no \\
Irritates peritoneum? & yes & no & no & no \\
Uses standard insufflators? & yes & yes & yes & no \\
Hazardous to personnel? & no & yes & no & no \\
Increases $\mathrm{PCO}_{2}$ ? & yes & no & no & $\begin{array}{l}\text { no } \\
\text { Delivered at room temperature? }\end{array}$ \\
& no $\left(15^{\circ} \mathrm{C}\right)$ & no & yes & yes \\
\hline
\end{tabular}

Table 2. Maximum doses of different gases tolerated intravascularly before the occurrence of severe symptoms or death in animal experiments

\begin{tabular}{lllll}
\hline Study - animal model & Argon & Helium & $\mathrm{CO}_{2}$ & Air \\
\hline Junghans 2000 - pigs & - & $<0.1 \mathrm{ml} / \mathrm{kg} / \mathrm{min}$ & $0.5 \mathrm{ml} / \mathrm{kg} / \mathrm{min}$ & - \\
Junghans 1999 - pigs & $<20 \mathrm{ml}$ bolus & - & $30 \mathrm{ml}$ bolus & - \\
Rudston 1997 - pigs & - & $<120 \mathrm{ml}$ bolus & $300 \mathrm{ml}$ bolus & - \\
Wolf 1994 - dogs & - & $<5 \mathrm{ml}$ bolus & $10 \mathrm{ml}$ bolus & - \\
Adornato $1978-\operatorname{dogs}$ & - & - & - & $3-8 \mathrm{ml}$ bolus \\
\hline
\end{tabular}

and air are at increased risk for embolization (table 1). Nitrous oxide is only slightly less soluble than $\mathrm{CO}_{2}$ and may have an advantage over the other gases if intravenous embolization occurs. However, it can cause combustion, being hazardous both to the patient and personnel [49].

The number of the clinical events and complications is related directly to the type and amount of gas insufflated. Intravascular presence of small amounts of soluble gas like $\mathrm{CO}_{2}$ probably occurs frequently without having any clinical consequence, whereas large amounts of a soluble gas or smaller amounts of an insoluble gas (air, nitrous oxide) may cause death. When studied with transesophageal echocardiography, $68 \%$ of asymptomatic patients have $\mathrm{CO}_{2}$ bubbling in the right chamber of the heart during laparoscopic cholecystectomy [50]. Transcranial Doppler experiments have shown that $\mathrm{CO}_{2}$ bubbles may even reach the cerebral circulation [2]. Since $\mathrm{CO}_{2}$ is soluble in blood, a much larger amount of it must rapidly enter the vascular system before significant embolism can occur. The dose of gas leading to clinical complications or death in bolus or continuous infusion administration only has been assessed for different gases, in animal experiments. The maximum tolerated doses are presented in table 2. On the basis of a study in dogs, the $\mathrm{LD}_{50}$ for a 70-kg human would be $1,750 \mathrm{ml} \mathrm{CO}$ or $375 \mathrm{ml}$ air [51].
In another study the magnitude of physiological disturbances caused by $\mathrm{CO}_{2}$ was 6.5 times less than that of air [52]. These differences were attributed to the high solubility of $\mathrm{CO}_{2}$, the buffering capacity of blood for $\mathrm{CO}_{2}$, and the rapid excretion of $\mathrm{CO}_{2}$ through the lungs.

Clinically, gas embolism can present as profound hypotension, dyspnea, cyanosis and arrhythmias or asystole. A mill-wheel murmur can be auscultated. There is an initial sudden increase in the end-tidal $\mathrm{CO}_{2}$ concentration, which decreases later due to cardiovascular collapse. If a gas embolism is suspected, a series of measures have to be immediately performed including [53-56]:

- Deflation of pneumoperitoneum.

- Placement of the patient in Durant's position (left lateral decubitus with head down position) which allows the gas to rise into the apex of the right ventricle and prevents its entry into the pulmonary artery. The Trendelenburg position is also sufficient as it has the same effect.

- Hyperventilation and administration of $100 \%$ oxygen helps rapid $\mathrm{CO}_{2}$ elimination.

- Aggressive cardiopulmonary resuscitation and a central venous catheter should be placed to aspirate the gas. 
Table 3. Differential diagnosis of capnothorax in the presence of subcutaneous emphysema

\begin{tabular}{lll}
\hline Findings & Subcutaneous emphysema & Capnothorax \\
\hline $\mathrm{EtCO}_{2}$ & increased & increased \\
Pulse oximetry & unchanged & - unchanged if minor \\
& & - oxygen desaturation if larger \\
Airway pressure & unchanged & increased \\
Reduced air entry & no & yes \\
Hyperresonance over hemithorax & no & yes \\
Swelling and crepitus & yes & absent if pure \\
Radiographs & gas in subcutaneous tissue & displaced lung; in severe cases the mediastinum \\
& & may be shifted \\
\hline
\end{tabular}

- Hyperbaric oxygen is less useful than for air embolisms because $\mathrm{CO}_{2}$ is more soluble and there is a high pressure gradient between the blood and $\mathrm{CO}_{2}$ bubbles (over $600 \mathrm{~mm} \mathrm{Hg}$ ) which encourages reabsorption. Use of this technique is only justified if the chamber is available within a short period of time and if it is possible to continue reviving the patient during the oxygen therapy session.

\section{Subcutaneous Emphysema}

Subcutaneous emphysema has been noted in $0.3-3.0 \%$ of laparoscopic procedures [46, 57]. Commonly, the gas passes through any disruption of the peritoneum into the subcutaneous tissue and into the retroperitoneal tissue. It is rarely the consequence of inadvertent placement of trocars and direct insufflation into the subcutaneous tissue. It can extend further on larger areas and even to the mediastinum and pleura, thus being the cause of pneumomediastinum and pneumothorax. The reverse situation is also possible, i.e. the extension of a pneumomediastinum into the subcutaneous tissue.

Mild-to-severe, localized or generalized subcutaneous emphysemas generally do not have clinical consequences. But it might point to a concurrent pneumomediastinum or pneumothorax, which may equally be its cause or effect. If there is an involvement of the neck it is also important to monitor the upper airway for obstruction. As the subcutaneous emphysema constitutes an important reservoir of $\mathrm{CO}_{2}$ into the body, it leads to an increase in end-tidal $\mathrm{CO}_{2}$ concentrations and therefore increased ventilation is required.

\section{Pneumothorax and Pneumomediastinum}

Since the most used gas in laparoscopy is $\mathrm{CO}_{2}$, the correct terms to define its pathological presence in the otherwise virtual pleural or pericardiac cavities should use the prefix capno- instead of pneumo-. Although capnothorax is more expected to occur during laparoscopy, a pneumothorax is also possible since the peak and plateau airway pressures of ventilation are higher than in open surgery and could favor, for example, the rupture of a congenital bulla.

Most of the cases of capnothorax occur during those laparoscopic procedures performed near the diaphragm (fundoplications, adrenalectomy) and are obviously caused by accidental diaphragmatic injuries [58-62]. Beside those situations, there are many other possible routes for gas to enter the thoracic cavity during pneumoperitoneum. Postulated sites are via any congenital diaphragmatic defects (e.g. foramen of Morgagni or foramen of Bochdalek) [63, 64], around the esophageal and aortic hiatus and via any procedure that can damage the falciform ligament (e.g. during insertion of a Veress needle). Occasionally, however, pneumothorax may develop as a result of $\mathrm{CO}_{2}$ dissecting and spreading through retroperitoneum or by the extension of a subcutaneous emphysema up to pleura. There are even reports of subcutaneous emphysema after laparoscopic extraperitoneal inguinal hernia repair, which extended and produced pneumothorax and pneumomediastinum [65-70].

As mentioned above, the presence of subcutaneous emphysema should always lead to the suspicion of a capnothorax. Since in both cases, subcutaneous emphysema and capnothorax, the end-tidal $\mathrm{CO}_{2}$ pressure is increased, the presence of the capnothorax is indicated by oxygen desaturation, increased airway pressure and reduced air entry, and should be confirmed by radiography (table 3 ).

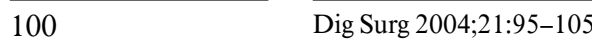


Occurrence of a capnothorax does not usually require placement of a chest drain, since carbon dioxide gas in the pleural cavity is rapidly reabsorbed at the completion of the procedure, allowing the lung to re-expand rapidly [71, 72]. Meanwhile, the use of positive end-expiratory pressure may largely correct the pathophysiological changes (decrease in total lung thorax compliance, increase in airway pressures, increase in $\mathrm{CO}_{2}$ absorption, increase in $\mathrm{PaCO}_{2}$ and end-tidal concentration of $\mathrm{CO}_{2}$ ) [3]. Only a moderate to severe capnothorax requires the placement of an intercostal chest tube.

\section{Renal Complications}

A pneumoperitoneum induces important changes in the physiology of the kidneys. The most common result is oliguria [73]. The main reasons for oliguria during laparoscopy include:

- Direct mechanical compression of renal arteries, veins and parenchyma $[74,75]$.

- The vicious circle of reduced renal perfusion $\rightarrow$ activation of renin-angiotensin-aldosterone system $\rightarrow$ renal cortical vasoconstriction [76].

- Increased antidiuretic hormone (ADH, vasopressin) $[76,77]$.

- Reduced cardiac output [78].

All of these factors depend on the amount of intraabdominal pressure and many experimental studies have documented the inverse correlation between intra-abdominal pressure and both renal perfusion and urine output $[74,75,79]$. At $15 \mathrm{~mm} \mathrm{Hg}$ the cortical renal flow decreases by $28 \%$, medullar renal flow decreases by $31 \%$ [80], glomerular filtration rate decreases to $18-31 \%$ of normal values [81] and urine output is below $0.5 \mathrm{ml} / \mathrm{min}$. This is a functional (prerenal) acute renal failure, which is generally reversible after $2 \mathrm{~h}$ postoperatively [75]. Prolonged renal hypoperfusion carries the risk for acute tubular necrosis and its consequences. Until now, the clinical significance of some urinary markers for the damage of renal tubules, like $\mathrm{N}$-acetyl-beta- $D$-glucosaminidase, has not been established [24, 81, 82], but some prophylactic actions are available and can easily be taken before acute tubular necrosis occurs. The easiest method for maintaining renal perfusion is the application of a sufficient intravascular volume loading before and during pneumoperitoneum. Low dose dopamine $2 \mu \mathrm{g} / \mathrm{kg} / \mathrm{min}$ can prevent renal dysfunction which is commonly associated with long-lasting surgical laparoscopic procedures performed with higher pressures of pneumoperitoneum $(\sim 15 \mathrm{~mm}$
$\mathrm{Hg}$ ) [83]. Urine output is significantly higher when insufflation of gas at body temperature is used as compared with room temperature $\mathrm{CO}_{2}$ insufflation. Warm insufflation probably causes a local renal vasodilation and may be beneficial to patients with borderline renal function [20]. Esmolol inhibits the release of renin and blunts the pressor response to induction and maintenance of pneumoperitoneum. Therefore, it may protect the kidneys against renal ischemia during laparoscopy [24, 84]. Non-steroidal anti-inflammatory drugs (NSAIDs), widely used for pain management, can cause renal medullary vasoconstriction that may induce acute tubular necrosis if added to the previous vasoconstriction caused by pneumoperitoneum [85, 86]. Therefore, NSAIDs, both the 'older' ones and the new selective COX-2 inhibitors (selective inhibitors of cyclooxygenase- 2 enzyme) should be avoided preoperatively in patients with impaired renal function or renal diseases.

\section{Splanchnic Ischemia}

Experimental animal studies in rats and pigs have shown a decrease in splanchnic macro- and microcirculation depending on the amount of intra-abdominal pressure [87-89]. The immediate consequences of this relative ischemia were an elevation of various hepatic enzymes, including GOT (glutamic oxaloacetic transaminase) and GPT (glutamic pyruvic transaminase), reflecting hepatocytic damage [90], an impaired function of the Kupffer cells [91], a drop in gastric intramucosal pH [92], an increase in bacterial translocation from the gut, and an increased production of oxygen-derived free radicals [93]. These experimental results were obtained using intraabdominal pressures ranging from 7 to $30 \mathrm{~mm} \mathrm{Hg}$. It is not shown that the effects of the pressures used are equivalent to those in humans and animals, since there is a significant disproportion between the volume of their abdominal cavities.

Clinical studies in patients are rare and consist of only small groups of patients. A very frequently cited study [94] assessed the splanchnic circulatory changes during highpressure $\mathrm{CO}_{2}$ pneumoperitoneum. An increase of $5 \mathrm{~mm}$ $\mathrm{Hg}$, from 10 to $15 \mathrm{~mm} \mathrm{Hg}$, of the intra-abdominal pressure resulted in a blood flow decrease by $40-54 \%$ to the stomach, by $32 \%$ to the jejunum, by $44 \%$ to the colon, by $39 \%$ to the liver, and by $60 \%$ to the peritoneum. Meanwhile, splanchnic blood flow decreased along with operative time, in spite of a constant intra-arterial pressure. But in humans, the consequences of splanchnic hypoperfusion seem to be milder compared to those encountered in animals. 
In laparoscopic cholecystectomy performed at the pressure $12 \mathrm{~mm} \mathrm{Hg}$, some studies found no changes in gastric mucosal tonometric values and other studies found a non-significant increase of the gastric mucosal $\mathrm{pH}$ (pHi) compared to 'open' or 'gasless' cholecystectomy [95-97]. Few studies showed increased levels of aminotransferase (alanine aminotransferase, aspartate aminotransferase) and also of alcohol dehydrogenase and glutathione S-transferase but the phenomenon is transient as these enzymes returned to normal values within 1-3 days [98-101]. These changes are clinically silent in patients with a normal liver function. Even in selected patients of Child-Pugh classes A and B with compensated cirrhosis some laparoscopic procedures (cholecystectomy, appendectomy, splenectomy) seem to be safe, in any case safer than the 'open' procedures [102-104]. Another concern is that free radicals are generated at the end of the laparoscopic procedure, possibly as a result of an ischemia-reperfusion phenomenon induced by the inflation and deflation of the pneumoperitoneum [105]. There are concerns about the possible oncological consequences since substantial experimental evidence exists implicating that both oxygen- and organic-free radical intermediaries are involved in multiple stages of chemical carcinogenesis (e.g. the nitric oxide pathway appears to play a key role in tumor angiogenesis).

Although the increased level of nitric oxide (implicated in the microvascular dysfunction associated with reperfusion) and malondialdehyde (the end product of lipid peroxidation) stands for an increased splanchnic production of free radicals after laparoscopy [97], many studies assessing different markers of oxidative stress including thiobarbituric acid-reactive substances, plasma total antioxidant status, uric acid, superoxide dismutase, catalase, reduced and oxidized glutathione, and glutathione peroxidase, found significantly less global oxidative stress than in open surgery [106]. Obviously, the influence of reperfusion related mechanisms after laparoscopy and the production of free radicals are smaller than the role of total surgical injury during open surgery [107-109].

\section{Conclusions}

The main pathophysiological changes during laparoscopy refer to the cardiovascular system where they translate into a slight increase in the incidence of arrhythmias and cardiac arrest. All other intraoperative hemodynamic alterations can be effectively prevented and controlled. Although there are important pulmonary pathophysiological changes, hypercarbia, hypoxemia and barotrauma rarely occur due to the appropriate ventilation monitoring and techniques. As long as $\mathrm{CO}_{2}$ remains the most used gas, significant embolism occurs rarely. The use of other gases (helium and argon) that may have advantages over $\mathrm{CO}_{2}$ regarding the changes in cardiorespiratory and intraperitoneal immunological status is impeded by their greater risk of embolism. Subcutaneous emphysema does not have clinical consequences but a concurrent capnothorax should be excluded. Usually, because of the high solubility of $\mathrm{CO}_{2}$, capnothorax is asymptomatic and may be treated conservatively. The alteration in splanchnic perfusion, as well as the systemic hemodynamic changes are proportional to the increased intra-abdominal pressure. Maintaining intra-abdominal pressure under $12 \mathrm{~mm}$ $\mathrm{Hg}$ reduces the incidences of these changes leading to minimal and transient consecutive organ dysfunction and without consequences for the outcome. It is the merit of the anesthesiology team to not let the pathophysiological changes transform into complications, and the surgeon has to be aware that a low insufflation pressure diminishes the pathophysiologic responses and avoids most of the complications.

\section{References}

1 Hsieh CH: Laparoscopic cholecystectomy for patients with chronic obstructive pulmonary disease. Laparoendosc Adv Surg Tech [A] 2003;13:5-9.

2 Neudecker J, Sauerland S, Neugebauer E, Bergamaschi R, Bonjer HJ, Cuschieri A, Fuchs KH, Jacobi C, Jansen FW, Koivusalo AM, Lacy A, McMahon MJ, Millat B, Schwenk W: The EAES clinical practice guidelines on pneumoperitoneum for laparoscopic surgery. Surg Endosc 2002;16:1121-1143.
3 Joris JL, Noirot DP, Legrand MJ, Jacquet NJ, Lamy ML: Hemodynamic changes during laparoscopic cholecystectomy. Anesth Analg 1993; 75:1067-1071.

4 Cunningham AJ, Turner J, Rosenbaum S, Rafferty T: Transoesophageal echocardiographic assessment of haemodynamic function during laparoscopic cholecystectomy. Br J Anaesth 1993; 70:621-625.
5 Critchley LAH, Critchley JAJH, Gin T: Haemodynamic changes in patients undergoing laparoscopic cholecystectomy: Measurement by transthoracic electrical bioimpedance. $\mathrm{Br} \mathrm{J}$ Anaesth 1993;70:681-683.

6 O'Leary E, Hubbard K, Tormey W, Cunningham AJ: Laparoscopic cholecystectomy: Haemodynamic and neuroendocrine responses after pneumoperitoneum and changes in position. Br J Anaesth 1996;76:640-644. 
7 Branche PE, Duperret SL, Sagnard PE, Boulez JL, Petit PL, Viale JP: Left ventricular loading modifications induced by pneumoperitoneum: A time course echocardiographic study. Anesth Analg 1998;86:482-487.

8 Galizia G, Prizio G, Lieto E, Castellano P, Pelosio L, Imperatore V, Ferrara A, Pignatelli C: Hemodynamic and pulmonary changes during open, carbon dioxide pneumoperitoneum and abdominal wall-lifting cholecystectomy: A prospective, randomized study. Surg Endosc 2001; 15:477-483.

9 De Waal EE, Kalkman CJ: Haemodynamic changes during low-pressure carbon dioxide pneumoperitoneum in young children. Paediatr Anaesth 2003;13:18-25.

10 Chui PT, Gin T, Oh TE: Anaesthesia for laparoscopic general surgery. Anaesth Intensive Care 1993;21:163-171.

11 Tobias JD: Anesthetic considerations for laparoscopy in children. Semin Laparosc Surg 1998;5:60-66.

12 Lopez-Herranz GP: Complicaciones transoperatorias asociadas al capnoperitoneo en cirugia laparoscopica. Rev Med Hosp General Mexico 2002;65:149-158.

13 Magrina JF: Complications of laparoscopic surgery. Clin Obstet Gynecol 2002;45:469_ 480.

14 Myles PS: Bradyarrhythmias and laparoscopy: A prospective study of heart rate changes with laparoscopy. Aust NZ J Obstet Gynaecol 1991; 31:171-173.

15 Keenan RL, Boyan CP: Decreasing frequency of anesthetic cardiac arrests. J Clin Anesth 1991:3:354-357.

16 Lee A, Lum ME: Measuring anaesthetic outcomes. Anaesth Intens Care 1996;24:685-693.

17 Korell M, Schmaus F, Strowitzki T, Schneeweiss SG, Hepp H: Pain intensity following laparoscopy. Surg Laparosc Endosc 1996;6: 375-379.

18 Josephs LG, Este-McDonald JR, Birkett DH, Hirsch EF: Diagnostic laparoscopy increases intracranial pressure. J Trauma 1994;36:815818; discussion 818-819.

19 Koivusalo AM, Lindgren L: Effects of carbon dioxide pneumoperitoneum for laparoscopic cholecystectomy. Acta Anaesthesiol Scand 2000;44:834-841.

20 Backlund M, Kellokumpu I, Scheinin T, von Smitten K, Tikkanen I, Lindgren L: Effect of temperature of insufflated $\mathrm{CO}_{2}$ during and af ter prolonged laparoscopic surgery. Surg Endosc 1998;12:1126-1130.

21 Schwenk W, Haase O, Junghans T: Perspectives in sequential pneumatic compression of the lower extremities (SCD) for laparoscopic surgery. Acta Chir Belg 2002;102:83-91.

22 Cunningham AJ: Anesthetic implications of laparoscopic surgery. Yale J Biol Med 1998;71: 551-578.

23 Leonard IE, Cunningham AJ: Anaesthetic considerations for laparoscopic cholecystectomy. Best Pract Res Clin Anaesthesiol 2002;16:120.
24 Koivusalo AM, Scheinin M, Tikkanen I, YliSuomu T, Ristkari S, Laakso J, Lindgren L: Effects of esmolol on haemodynamic response to $\mathrm{CO}_{2}$ pneumoperitoneum for laparoscopic surgery. Acta Anaesthesiol Scand 1998;42: 510-517.

25 Laisalmi M, Koivusalo AM, Valta P, Tikkanen I, Lindgren L: Clonidine provides opioid-sparing effect, stable hemodynamics, and renal integrity during laparoscopic cholecystectomy. Surg Endosc 2001;15:1331-1335.

26 Barczynski M, Herman RM: A prospective randomized trial on comparison of low-pressure (LP) and standard-pressure (SP) pneumoperitoneum for laparoscopic cholecystectomy. Surg Endosc 2003;17:533-538.

27 Hirvonen EA, Poikolainen EO, Paakkonen ME, Nuutinen LS: The adverse hemodynamic effects of anesthesia, head-up tilt, and carbon dioxide pneumoperitoneum during laparoscopic cholecystectomy. Surg Endosc 2000;14: 272-277.

28 Makinen MT, Yli-Hankala A: The effect of laparoscopic cholecystectomy on respiratory compliance as determined by continuous spirometry. J Clin Anesth 1996;8:119-122.

29 Pelosi P, Foti G, Cereda M, Vicardi P, Gattinoni L: Effects of carbon dioxide insufflation for laparoscopic cholecystectomy on the respiratory system. Anaesthesia 1996;51:744-749.

30 Rauh R, Hemmerling TM, Rist M, Jacobi KE: Influence of pneumoperitoneum and patient positioning on respiratory system compliance. J Clin Anesth 2001;13:361-365.

31 Garcia-Perez M, Belda F, Lla J, Aguilar G, Soro M, Marti F, Guillen A: Changes in chest wall and lung compliance during laparoscopic cholecystectomy. Rev Esp Anestesiol Reanim 2001;48:171-175.

32 Haydon GH, Dillon J, Simpson KJ, Thomas $\mathrm{H}$, Hayes PC: Hypoxemia during diagnostic laparoscopy: A prospective study. Gastrointest Endosc 1996;44:124-128.

33 Loeckinger A, Kleinsasser A, Hoermann C, Gassner M, Keller C, Lindner KH: Inert gas exchange during pneumoperitoneum at incremental values of positive end-expiratory pressure. Anesth Analg 2000;90:466-471.

34 Sandbu R, Birgisdottir B, Arvidsson D, Sjostrand U, Rubertsson S: Optimal positive endexpiratory pressure (PEEP) settings in differential lung ventilation during simultaneous unilateral pneumothorax and laparoscopy: An experimental study in pigs. Surg Endosc 2001; 15:1478-1483.

35 Hazebroek EJ, Haitsma JJ, Lachmann B, Bonjer HJ: Mechanical ventilation with positive end-expiratory pressure preserves arterial oxygenation during prolonged pneumoperitoneum. Surg Endosc 2002; 16:685-689.

36 Moffa SM, Quinn JV, Slotman GJ: Hemodynamic effects of carbon dioxide pneumoperitoneum during mechanical ventilation and positive end-expiratory pressure. J Trauma 1993;35:613-617; discussion 617-618.
37 Luz CM, Polarz H, Bohrer H, Hundt G, Dorsam J, Martin E: Hemodynamic and respiratory effects of pneumoperitoneum and PEEP during laparoscopic pelvic lymphadenectomy in dogs. Surg Endosc 1994;8:25-27.

38 Woolley DS, Puglisi RN, Bilgrami S, Quinn JV, Slotman GJ: Comparison of the hemodynamic effects of gasless abdominal distention and $\mathrm{CO}_{2}$ pneumoperitoneum during incremental positive end-expiratory pressure. J Surg Res 1995;58:75-80.

39 Kraut EJ, Anderson JT, Safwat A, Barbosa R, Wolfe BM: Impairment of cardiac performance by laparoscopy in patients receiving positive end-expiratory pressure. Arch Surg 1999;134:76-80.

40 Pang CK, Yap J, Chen PP: The effect of an alveolar recruitment strategy on oxygenation during laparoscopic cholecystectomy. Anaesth Intens Care 2003;31:176-180.

41 Schulte-Steinberg H, Meyer G, Forst H: Are high risk patients candidates for minimally invasive surgery with $\mathrm{CO}_{2}$ pneumoperitoneum? Viewpoint from anesthesiology. Chirurg 1996; 67:72-76

42 Hasukic S, Mesic D, Dizdarevic E, Keser D, Hadziselimovic S, Bazardzanovic M: Pulmonary function after laparoscopic and open cholecystectomy. Surg Endosc 2002;16:163-165.

43 Schwenk W, Bohm B, Witt C, Junghans T, Grundel K, Muller JM: Pulmonary function following laparoscopic or conventional colorectal resection: A randomized controlled evaluation. Arch Surg 1999;134:6-12; discussion 13.

44 Nguyen NT, Lee SL, Goldman C, Fleming N, Arango A, McFall R, Wolfe BM: Comparison of pulmonary function and postoperative pain after laparoscopic versus open gastric bypass: A randomized trial. J Am Coll Surg 2001;192: 469-476; discussion 476-477.

45 Law WL, Chu KW, Tung PH: Laparoscopic colorectal resection: A safe option for elderly patients. J Am Coll Surg 2002;195:768-773.

46 Bonjer HJ, Hazebroek EJ, Kazemier G, Giuffrida MC, Meijer WS, Lange JF: Open versus closed establishment of pneumoperitoneum in laparoscopic surgery. Br J Surg 1997;84:599_ 602.

47 Shulman D, Aronson HB: Capnography in the early diagnosis of carbon dioxide embolism during laparoscopy. Can Anaesth Soc J 1984; 31:455-459.

48 Junghans T, Böhm B, Gründel K, Scheiba-Zórron R, Muller JM: Effects of induced intravenous helium and $\mathrm{CO}_{2}$ embolism on the cardiovascular system. Minimal Invas Chir 1998:5256.

49 Menes T, Spivak H: Laparoscopy: Searching for the proper insufflation gas. Surg Endosc 2000;14:1050-1056.

50 Derouin M, Couture P, Boudreault D, Girard D, Gravel D: Detection of gas embolism by transesophageal echocardiography during laparoscopic cholecystectomy. Anesth Analg 1996; 82:119-124. 
51 Graff TD, Arbegast NR, Phillips OC: Gas embolism: A comparative study of air and carbon dioxide as embolic agents in the systemic venous system. Am J Obstet Gynecol 1959;78: 259-265.

52 Steffey EP, Johnson BH, Eger EI: Nitrous oxide intensifies the pulmonary arterial pressure response to venous injection of carbon dioxide in the dog. Anesthesiology 1980;52:52-55.

53 Haroun-Bizri S, El Rassi T: Successful resuscitation after catastrophic carbon dioxide embolism during laparoscopic cholecystectomy. Eur J Anaesthesiol 2001;18:118-121.

54 Souders JE: Pulmonary air embolism. J Clin Monit Comput 2000;16:375-383.

55 Archer DP, Pash MP, MacRae ME: Successful management of venous air embolism with inotropic support. Can J Anaesth 2001;48:204208.

56 Appel JM, Bonde J, Madsen J: Venous gas embolisms. Ugeskr Laeger 1994;156:68526856.

57 Hashizume M, Sugimachi K: Needle and trocar injury during laparoscopic surgery in Japan. Surg Endosc 1997;11:1198-1201.

58 Del Pizzo JJ, Jacobs SC, Bishoff JT, Kavoussi LR, Jarrett TW: Pleural injury during laparoscopic renal surgery: Early recognition and management. Urol 2003;169:41-44.

59 Leong LM, Ali A: Carbon dioxide pneumothorax during laparoscopic fundoplication. Anaesthesia 2003;58:97.

60 Hahnloser D, Schumacher M, Cavin R, Cosendey B, Petropoulos P: Risk factors for complications of laparoscopic Nissen fundoplication. Surg Endosc 2002;16:43-47.

61 Joris JL, Chiche JD, Lamy ML: Pneumothorax during laparoscopic fundoplication: Diagnosis and treatment with positive end-expiratory pressure. Anesth Analg 1995;81:993-1000.

62 Watson DI, de Beaux AC: Complications of laparoscopic antireflux surgery. Surg Endosc 2001;15:344-352.

63 Stokes KB: Unusual varieties of diaphragmatic herniae. Prog Pediatr Surg 1991;27:127-147.

64 Azocar RJ, Rios JR, Hassan M: Spontaneous pneumothorax during laparoscopic adrenalectomy secondary to a congenital diaphragmatic defect. J Clin Anesth 2002;14:365-367.

65 Ferzli GS, Kiel T, Hurwitz JB, Davidson P, Piperno B, Fiorillo MA, Hayek NE, Riina LL, Sayad P: Pneumothorax as a complication of laparoscopic inguinal hernia repair. Surg Endosc 1997;11:152-153.

66 Toyoshima Y, Tsuchida H, Namiki A: Pneumothorax during endoscopic extraperitoneal herniorrhaphy. Anesthesiology 1998;89:1040.

67 Harkin CP, Sommerhaug EW, Mayer KL: An unexpected complication during laparoscopic herniorrhaphy. Anesth Analg 1999;89:15761578.

68 Ramia JM, Pardo R, Cubo T, Padilla D, Hernandez-Calvo J: Pneumomediastinum as a complication of extraperitoneal laparoscopic inguinal hernia repair. JSLS 1999;3:233-423.

69 Browne J, Murphy D, Shorten G: Pneumomediastinum, pneumothorax and subcutaneous emphysema complicating MIS herniorrhaphy. Can J Anaesth 2000;47:69-72.
70 Hagopian EJ, Steichen FM, Lee KF, Earle DB: Gas extravasation complicating laparoscopic extraperitoneal inguinal hernia repair. Surg Endosc 2001;15:324.

71 Hawasli A: Spontaneous resolution of massive laparoscopy-associated pneumothorax: The case of the bulging diaphragm and review of the literature. Laparoendosc Adv Surg Tech A 2002; 12:77-82.

72 Venkatesh R, Kibel AS, Lee D, Rehman J, Landman J: Rapid resolution of carbon dioxide pneumothorax (capno-thorax) resulting from diaphragmatic injury during laparoscopic nephrectomy. J Urol 2002;167:1387-1388.

73 Nguyen NT, Perez RV, Fleming N, Rivers R, Wolfe BM: Effect of prolonged pneumoperitoneum on intraoperative urine output during laparoscopic gastric bypass. J Am Coll Surg 2002; 195:476-483.

74 Chiu AW, Azadzoi KM, Hatzichristou DG, Siroky MB, Krane RJ, Babayan RK: Effects of intra-abdominal pressure on renal tissue perfusion during laparoscopy. J Endourol 1994;8: 99-103.

75 Chiu AW, Chang LS, Birkett DH, Babayan RK: The impact of pneumoperitoneum, pneumoretroperitoneum, and gasless laparoscopy on the systemic and renal hemodynamics. J Am Coll Surg 1995;181:397-406.

76 Dolgor B, Kitano S, Yoshida T, Bandoh T, Ninomiya $\mathrm{K}$, Matsumoto $\mathrm{T}$ : Vasopressin antagonist improves renal function in a rat model of pneumoperitoneum. J Surg Res 1998;79: 109-114.

77 Hazebroek EJ, de Vos tot Nederveen Cappel R, Gommers D, van Gelder T, Weimar W, Steyerberg EW, Bonjer HJ, IJzermans JN: Antidiuretic hormone release during laparoscopic donor nephrectomy. Arch Surg 2002;137:600604; discussion 605.

78 Are C, Kutka M, Talamini M, Hardacre J, Mendoza-Sagaon M, Hanley E, Toung T: Effect of laparoscopic antireflux surgery upon renal blood flow. Am J Surg 2002;183:419_ 423.

79 Koivusalo AM, Kellokumpu I, Ristkari S, Lindgren L: Splanchnic and renal deterioration during and after laparoscopic cholecystectomy: A comparison of the carbon dioxide pneumoperitoneum and the abdominal wall lift method. Anesth Analg 1997;85:886-891.

80 McDougall EM, Bennett HF, Monk TG, Siegel CL, Li D, McFarland EG, Clayman RV, Sharp T, Rayala HJ, Miller SB, Haacke EM: Functional MR imaging of the porcine kidney: Physiologic changes of prolonged pneumoperitoneum. JSLS 1997;1:29-35.

81 Cisek LJ, Gobet RM, Peters CA: Pneumoperitoneum produces reversible renal dysfunction in animals with normal and chronically reduced renal function. J Endourol 1998;12:95100.

82 Micali S, Silver RI, Kaufman HS, Douglas VD, Marley GM, Partin AW, Moore RG, Kavoussi LR, Docimo SG: Measurement of urinary Nacetyl-beta- $D$-glucosaminidase to assess renal ischemia during laparoscopic operations. Surg Endosc 1999; 13:503-506.
83 Perez J, Taura P, Rueda J, Balust J, Anglada T, Beltran J, Lacy AM, Garcia-Valdecasas JC: Role of dopamine in renal dysfunction during laparoscopic surgery. Surg Endosc 2002;16: 1297-1301.

84 Coloma M, Chiu JW, White PF, Armbruster SC: The use of esmolol as an alternative to remifentanil during desflurane anesthesia for fast-track outpatient gynecologic laparoscopic surgery. Anesth Analg 2001;92:352-357.

85 Epstein M: Non-steroidal anti-inflammatory drugs and the continuum of renal dysfunction. J Hypertens 2002;20:S17-S23.

86 LeLorier J, Bombardier C, Burgess E, Moist L, Wright N, Cartier P, Huckell V, Hunt R, Nawar T, Tobe S: Practical considerations for the use of nonsteroidal anti-inflammatory drugs and cyclo-oxygenase- 2 inhibitors in hypertension and kidney disease. Can J Cardiol 2002; 18:1301-1308.

87 Windberger UB, Auer R, Keplinger F, Langle F, Heinze G, Schindl M, Losert UM: The role of intra-abdominal pressure on splanchnic and pulmonary hemodynamic and metabolic changes during carbon dioxide pneumoperitoneum. Gastrointest Endosc 1999;49:84-91.

88 Schafer M, Sagesser H, Reichen J, Krahenbuhl L: Alterations in hemodynamics and hepatic and splanchnic circulation during laparoscopy in rats. Surg Endosc 2001;15:1197-1201.

89 Yokoyama Y, Alterman DM, Sarmadi AH, Baveja R, Zhang JX, Huynh T, Clemens MG: Hepatic vascular response to elevated intraperitoneal pressure in the rat. J Surg Res 2002;105: 86-94.

90 Toens C, Schachtrupp A, Hoer J, Junge K, Klosterhalfen B, Schumpelick V: A porcine model of the abdominal compartment syndrome. Shock 2002;18:316-321.

91 Gutt CN, Kim ZG, Schemmer P, Krahenbuhl L, Schmedt CG: Impact of laparoscopic and conventional surgery on Kupffer cells, tumorassociated CD44 expression, and intrahepatic tumor spread. Arch Surg 2002;137:14081412 .

92 Knolmayer TJ, Bowyer MW, Egan JC, Asbun $\mathrm{HJ}$ : The effects of pneumoperitoneum on gastric blood flow and traditional hemodynamic measurements. Surg Endosc 1998;12:115-118.

93 Sare M, Yilmaz I, Hamamci D, Birincioglu M, Ozmen M, Yesilada O: The effect of carbon dioxide pneumoperitoneum on free radicals. Surg Endosc 2000;14:649-652.

94 Schilling MK, Redaelli C, Krahenbuhl L, Signer C, Buchler MW: Splanchnic microcirculatory changes during $\mathrm{CO}_{2}$ laparoscopy. $\mathrm{J}$ Am Coll Surg 1997;184:378-382.

95 Thaler W, Frey L, Marzoli GP, Messmer K Assessment of splanchnic tissue oxygenation by gastric tonometry in patients undergoing laparoscopic and open cholecystectomy. $\mathrm{Br} \mathrm{J}$ Surg 1996;83:620-624.

96 Makinen MT, Heinonen PO, Klemola UM, Yli-Hankala A: Gastric air tonometry during laparoscopic cholecystectomy: A comparison of two $\mathrm{PaCO}_{2}$ levels. Can J Anaesth 2001;48: 121-128. 
97 Ozmen MM, Kessaf Aslar A, Besler HT, Cinel I: Does splanchnic ischemia occur during laparoscopic cholecystectomy? Surg Endosc 2002; 16:468-471.

98 Andrei VE, Schein M, Margolis M, Rucinsk JC, Wise L: Liver enzymes are commonly elevated following laparoscopic cholecystectomy: Is elevated intra-abdominal pressure the cause? Dig Surg 1998;15:256-259.

99 Saber AA, Laraja RD, Nalbandian HI, Pablos-Mendez A, Hanna K: Changes in liver function tests after laparoscopic cholecystectomy: Not so rare, not always ominous. Am Surg 2000;66:699-702.

100 Kotake Y, Takeda J, Matsumoto M, Tagawa M, Kikuchi H: Subclinical hepatic dysfunction in laparoscopic cholecystectomy and laparoscopic colectomy. Br J Anaesth 2001;87: 774-777.

101 Tan M, Xu FF, Peng JS, Li DM, Chen LH, Lv BJ, Zhao ZX, Huang C, Zheng CX: Changes in the level of serum liver enzymes after laparoscopic surgery. World J Gastroenterol 2003;9:364-367.
102 Tsugawa K, Koyanagi N, Hashizume M, Tomikawa M, Ayukawa K, Akahoshi K, Sugimachi K: A comparison of an open and laparoscopic appendectomy for patients with liver cirrhosis. Surg Laparosc Endosc Percutan Tech 2001;11:189-194.

103 Tuech JJ, Pessaux P, Regenet N, Rouge C, Bergamaschi R, Arnaud JP: Laparoscopic cholecystectomy in cirrhotic patients. Surg Laparosc Endosc Percutan Tech 2002;12: 227-231.

104 Radu H, Osian G, Vlad L, Vieru V, Mutelica L: Comparative study of accidents and complications of laparoscopic cholecystectomy in cirrhotic and non cirrhotic patients. Rom J Gastroenterol 2002;11:13-17.

105 Glantzounis GK, Tselepis AD, Tambaki AP, Trikalinos TA, Manataki AD, Galaris DA, Tsimoyiannis EC, Kappas AM: Laparoscopic surgery-induced changes in oxidative stress markers in human plasma. Surg Endosc 2001; 15:1315-1319.
106 Taskin O, Buhur A, Birincioglu M, Burak F, Atmaca R, Yilmaz I, Wheeler JM: The effects of duration of $\mathrm{CO}_{2}$ insufflation and irrigation on peritoneal microcirculation assessed by free radical scavengers and total glutathione levels during operative laparoscopy. J Am Assoc Gynecol Laparosc 1998;5:129-133.

107 Gal I, Roth E, Lantos J, Varga G, Mohamed TJ, Nagy J: Surgical trauma induced by laparoscopic cholecystectomy. Orv Hetil 1998; 139:739-746.

108 Seven R, Seven A, Erbil Y, Mercan S, Burcak G: Lipid peroxidation and antioxidant state after laparoscopic and open cholecystectomy. Eur J Surg 1999;165:871-874.

109 Zulfikaroglu B, Koc M, Soran A, Isman FK, Cinel I: Evaluation of oxidative stress in laparoscopic cholecystectomy. Surg Today 2002; 32:869-874. 